Research Article

\title{
A Comparative Study to Assess the Quality of Life and Stress among Orphan and Non-orphan Children in Selected Areas of Bagalkot
}

\author{
Shivashankar H Kalagi', Santosh B Sajjan², Deelip S Natekar ${ }^{3}$
}

${ }^{1}$ MSc Nursing, ${ }^{2}$ Associate Professor, Dept. of Paediatric Nursing, ${ }^{3}$ Principal, BVVS Sajjalashree Institute of Nursing Sciences, Navanagar, Bagalkot, Karnataka, India.

DOI: https://doi.org/10.24321/2348.2133.202007

\section{I $\quad \mathbf{N} \quad \mathbf{F} \quad \mathbf{O}$}

\section{Corresponding Author:}

Santosh B Sajjan, Dept. of Paediatric Nursing, BVVS Sajjalashree Institute of Nursing Sciences, Navanagar, Bagalkot, Karnataka, India.

E-mail Id:

santoshsajjan83@gmail.com

Orcid Id:

https://orcid.org/0000-0001-6900-9650

How to cite this article:

Kalagi SH, Sajjan SB, Natekar DS. A Comparative Study to Assess the Quality of Life and Stress among Orphan and Non-orphan Children in Selected Areas of Bagalkot. Ind J Holist Nurs 2020; 11(4): 19-25.

Date of Submission: 2020-11-30

Date of Acceptance: 2020-12-19

\section{$\begin{array}{llllllll}\mathbf{A} & \mathbf{B} & \mathbf{S} & \mathbf{T} & \mathbf{R} & \mathbf{A} & \mathbf{C} & \mathbf{T}\end{array}$}

Introduction: The word orphan comes from the Greek word 'Orfanos' and refers to a child permanently bereaved of or abandoned by his or her parents.

Methods: A non-experimental descriptive comparative design has been adopted for the present study. The sample of the present study comprises orphan children residing in an orphanage and non-orphan children residing in selected areas of Bagalkot. The sample comprised 30 orphans and 30 non-orphans aged between 10 and 16 years. The data were collected by using self-report, structured closed-ended questionnaires for socio-demographic variables of children, selfadministered WHO Quality of life BREF scale, and PSS stress scale. The data obtained were analysed with the help of descriptive and inferential statistics.

Result: Findings related to the comparison between the level of stress among the orphan and non-orphan children revealed that majority of orphan children (76.66\%) had about moderate stress, $23.33 \%$ of the orphan children had high stress, and none of the children had a low level of stress, whereas among non-orphan children, majority (90\%) had moderate stress, $10 \%$ had low level stress, and none of them had high level stress.

The findings related to the comparison of levels of quality of life among the orphan and non-orphan children reveal that a high percentage of orphan children $(66.66 \%)$ had a moderate quality of life and some of them (33.33\%) had a poor quality of life, whereas a high number of non-orphan children (66.66\%) had a very good quality of life and some (33.33\%) had a good quality of life. No significant association was found between the quality of life and stress scores with the socio-demographic variables of orphan and non-orphan children.

Conclusion: The study concluded that orphan children need to improve their quality of life and decrease their level of stress.

Keywords: Quality of Life, Level of Stress, Perceived Stress Scale, WHOQOL-BREF Scale 


\section{Introduction}

"Every child deserves a chance of good life"

Childhood experiences determine the future social, emotional, and psychological dynamics and functioning of individuals in their adulthood life. Adverse and painful childhood experiences can sabotage the psychosocial wellbeing of children. According to UNICEF, "an orphan is a child who has lost one or both parents often through death". ${ }^{1}$

Post parental loss, children experience sorrow, anxiety, depression, and lack of support and care. The trauma of losing parents can have adverse effects on the quality of life of children and lead to psychosocial problems like feelings of mistrust, inferiority, shame, guilt, insecurity, stress, and improper conduct. To cope with psychosocial distress, children indulge in harmful activities like substance abuse, violence, and delinquent behaviour. ${ }^{2}$

\section{Need for Study}

Orphanhood and problems faced by the orphans have emerged as a serious threat to the community and national development. If the impending tragedy is to be averted, new and visionary policies and programmes aimed at improving their living condition and securing their future are urgently needed. ${ }^{3}$

According to WHO 2021 new report study on International charity, orphaned and abandoned children found that India is home to 20 million are orphans, a figure projected to increase by $2021 .{ }^{4}$

According to WHO report 2014, it is estimated that 143210 million orphans are living worldwide. Approximately there are 12.44 million orphans, and close to 40 million destitute children live in India. Each year, about a million new orphans are added to society in India. ${ }^{4,5}$

The perceived stress and poor quality of life among orphaned children have been portrayed in different studies by researchers. All the studies display a grave urgency because the stress which is faced by orphaned children can cause thwarted development.

\section{Review of Literature}

A study was conducted to examine the association of single and double orphanhood with depressive symptoms and emotional distress among children and adolescents in Namibia. A sample of 157 students from 3 schools including 84 non-orphans, 50 single orphans, and 23 double orphans was taken and Children's Depression Inventory (CDI) was administered. The results found that $21.9 \%$ of single orphans and double orphans and $11.9 \%$ of non-orphans exhibited depressive (stress) symptoms. The study provides evidence that orphanhood is associated with ill-mental health and that high rates of stress are present in approximately 1 in 6 children and adolescents in Namibia. ${ }^{6}$

\section{Methodology}

Research Approach: Non-experimental

Research Design: Descriptive comparative design

Duration of Study: 2 years

Ethical Clearance: Ethical clearance has been obtained from:

- The Institutional Ethics Committee of Shri. B.V.V.S, Sajjalashree Institute of Nursing Sciences, Bagalkot

- Permission from orphanage head

- Consent was obtained from the study participants (both orphan and non-orphans)

Research Variables: Study variables include stress and quality of life among orphan and non-orphan children.

Socio-demographic Variables: These include age, gender, religion, educational standard, duration of stay in orphanage, parental living status, hobbies of children, area of residence of non-orphans, Family monthly income of non-orphans, and educational status of father and mother.

\section{Settings of the Study}

The present study was conducted in Balakar and Balakiyar Balamandir (orphanages) Bagalkot and Muchakhandi and Viddyagir areas in Bagalkot.

\section{Population}

Target Population: In the present study, orphan children and non-orphan children.

Sample: Orphan children who were residing in orphanage and non-orphan children residing in selected areas of Bagalkot.

Sampling Size: The sample comprised 30 orphans and 30 non-orphans aged between 10 and 16 years.

Sampling Technique: A non-probability purposive sampling technique was adopted to select samples in the present study.

\section{Inclusion Criteria}

- Orphan children who were residing in selected orphanage at Bagalkot

- Orphan children who were aged between 10 and 16 years

- Non-orphan children who resided with their parents in selected areas of Bagalkot

- Orphan children and non-orphan children who all were able to cooperate during the study

- Orphan children and non-orphan children who could understand and speak Kannada language

- Orphan children and non-orphan children who were available at the time of data collection

\section{Exclusion Criteria}

- Orphan children and non-orphan children who were 
not willing to give written consent

- Orphan children and non-orphan children who were ill at the time of the study and were unable to provide data

Method of Data Collection: In the present study, the data was collected by the WHO-BREF quality assessment scale to assess the level of QOL and the perceived stress scale for assessing the level of stress.

\section{Description of the Final Tool}

The final format of the tool comprised of the following three parts.

Part 1: Socio-demographic variables which consist of information about age, gender, religion, educational standard, duration of stay in orphanage, parental living status, hobbies of children, area of residence of nonorphans, family monthly income of non-orphans, and educational status of father and mother.

Part 2: Consists of WHO-BREF quality assessment scale with 26 items to assess the quality of life among orphan and non-orphan children.

\section{Scoring of Items in WHO-BREF Scale}

There are 26 questions on the WHO-BREF scale, each scored from 1-5, comprising 4 domains, thus the maximum score is 130 and the minimum score is 26 .

Orphan and non-orphan children scores were divided into different categories on the basis of the levels of quality of life.

Table I.Levels of Quality of Life

\begin{tabular}{|c|c|}
\hline Scores & Quality of Life \\
\hline $105-130$ & Very Good Quality of Life \\
\hline $79-104$ & Good Quality of Life \\
\hline $53-78$ & Moderate Quality of Life \\
\hline $27-52$ & Poor Quality of Life \\
\hline $1-26$ & Very Poor Quality of Life \\
\hline
\end{tabular}

The 4 domains are:

- $\quad$ Physical Health comprises Q3, Q4, Q10, Q15, Q16, Q17, and Q18. The Physical Health domain score is obtained by the sum of all the values for each of these questions (after correcting the reverse coded questions).

- Psychological domain comprises Q5, Q6,Q7, Q11, Q19, and Q26.

- $\quad$ Social Relationships comprises Q20, Q21, and Q22.

- Environmental domain comprises Q8, Q9, Q12, Q13, Q14, Q23, Q24, and Q25.

Part 3: Consists of perceived stress scale with 10 items for assessing stress among orphan and non-orphan children.

\section{Scoring of Items in PSS Scale}

Individual scores on the PSS can range from 0 to 40 with higher scores indicating higher perceived stress.

Table 2.Perceived Stress Scale Scoring

\begin{tabular}{|c|c|c|}
\hline S. No. & Levels & Scores \\
\hline 1. & Low level & 0 to 13 \\
\hline 2. & Moderate level & 14 to 26 \\
\hline 3. & High level & 27 to 40 \\
\hline
\end{tabular}

There are 10 items on Percieved stress scale and are scored as mentioned below.

$0=$ Never, 1 = Almost Never, 2 = Sometimes, 3 = Fairly Often, 4 = Very Often

\section{Result}

Data analysis was done with the help of descriptive and inferential statistics.

\section{Part I: Description of Subjects with their Selected Socio-demographic Variables}

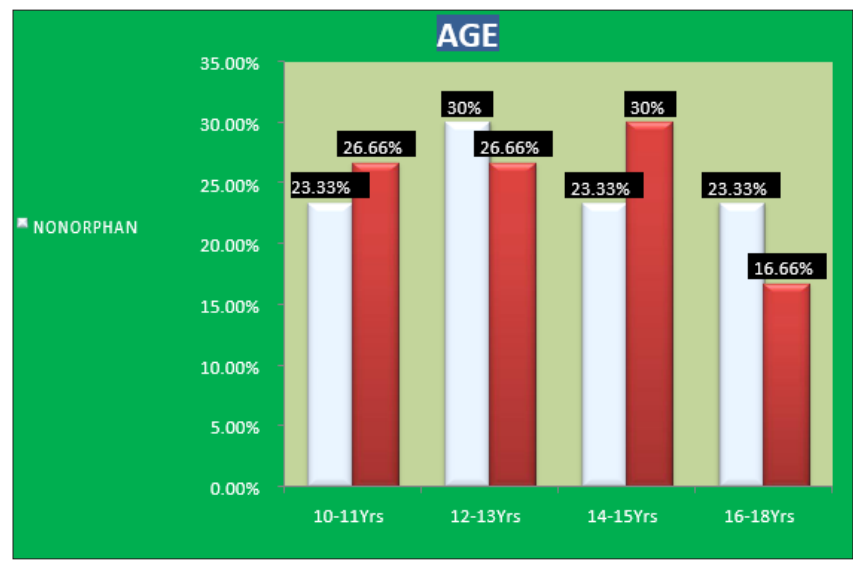

Figure I.Percentage-wise Distribution of Orphan and Non-orphan Children according to Age

Figure 1, depicts the percentage-wise distribution of samples according to their age. This figure shows that majority of non-orphan children (30\%) belonged to $12-13$ years of age, $23.33 \%$ belonged to the age group of $10-11$ years, $23.33 \%$ belonged to the age group of $14-15$ years, and $23.33 \%$ belonged to the age group of $16-18$ years, whereas among orphan children, most of the children (30\%) belonged to $14-15$ years of age, $26.66 \%$ belonged to $10-11$ years of age and $12-13$ years of age, and $16.66 \%$ belonged to the age group of 16 to 18 years.

According to Figure 2, majority of non-orphan children (70\%) were male, and $30 \%$ were female.

Among orphan children, majority (60\%) were female, and $40 \%$ were male. 


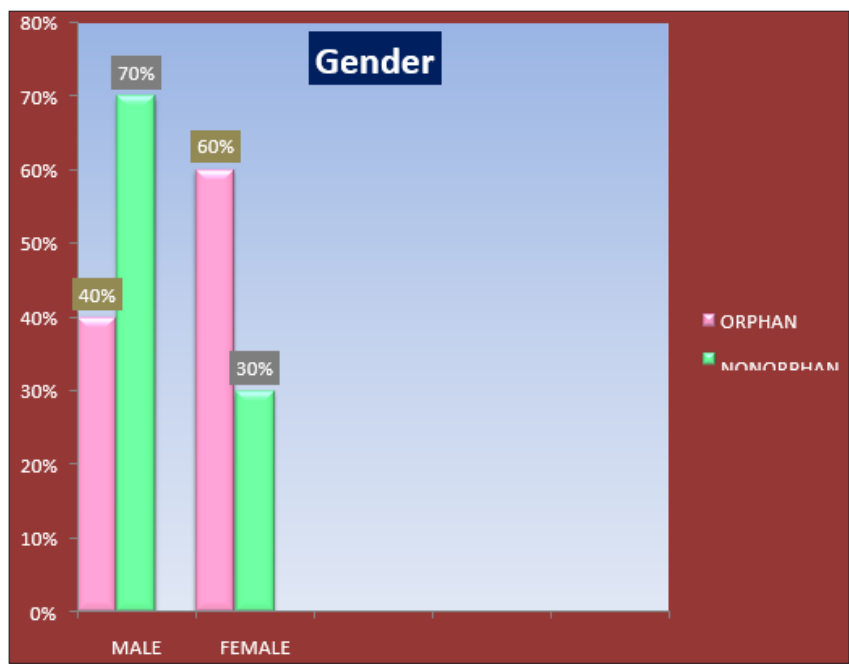

Figure 2.Percentage-wise Distribution of Orphan and Non-orphan Children according to their Gender

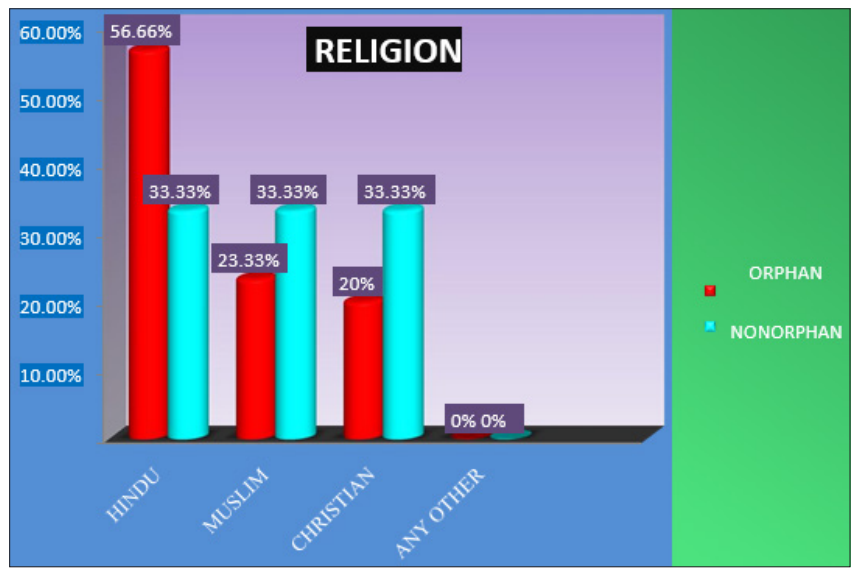

Figure 3.Percentage-wise Distribution of Orphan and Non-orphan Children according to their Religion

As shown in Figure 3, majority of orphan children (56.66\%) were Hindus, 23.33\% were Muslims, and 20\% were Christians, whereas $33.33 \%$ of the non-orphan children were Hindus, 33.33\% were Muslims, and 33.33\% were Christians.

Part 2: Assessment and Comparison of Stress among Orphan and Non-orphan Children in Selected Areas of Bagalkot

Table 3.Comparison between Levels of Stress among Orphan and Non-orphan Children

$\mathrm{n}=60$

\begin{tabular}{|c|c|c|c|c|c|}
\hline \multirow{2}{*}{$\begin{array}{c}\text { S. } \\
\text { No. }\end{array}$} & \multirow{2}{*}{ Level of Stress } & \multicolumn{2}{|c|}{$\begin{array}{c}\text { Orphan } \\
\text { Children }\end{array}$} & \multicolumn{2}{c|}{$\begin{array}{c}\text { Non-orphan } \\
\text { Children }\end{array}$} \\
\cline { 3 - 6 } & & $\mathbf{f}$ & $\%$ & $\mathbf{f}$ & $\%$ \\
\hline 1. & Low level & 00 & 00 & 03 & 10 \\
\hline 2. & Moderate level & 23 & 76.66 & 27 & 90 \\
\hline 3. & High level & 07 & 23.33 & 00 & 00 \\
\hline & Total & 30 & 100 & 30 & 100 \\
\hline
\end{tabular}

As shown in Table 3, most of the orphan children (76.66\%) had moderate stress, $23.33 \%$ had high stress, and there was no low-level stress among children, whereas among the non-orphan children, majority (90\%) had moderate stress, $10 \%$ had low-level stress, and none of the children had high-level stress.

Part 3: Assessment of Quality of Life among Orphan and Non-orphan Children in Selected Areas of Bagalkot Table 4.Quality of Life among Orphan and
Non-orphan Children

\begin{tabular}{|c|c|c|c|c|c|}
\hline \multirow{2}{*}{$\begin{array}{c}\text { Level of } \\
\text { QOL }\end{array}$} & \multirow{2}{*}{$\begin{array}{c}\text { Range of } \\
\text { Score }\end{array}$} & \multicolumn{2}{|c|}{$\begin{array}{c}\text { Orphan } \\
\text { Children }\end{array}$} & \multicolumn{2}{|c|}{$\begin{array}{c}\text { Non-orphan } \\
\text { Children }\end{array}$} \\
\cline { 3 - 6 } & Score & $\begin{array}{c}\text { Perce- } \\
\text { ntage }\end{array}$ & Score & $\begin{array}{c}\text { Perce- } \\
\text { ntage }\end{array}$ \\
\hline $\begin{array}{c}\text { Very Good } \\
\text { QOL }\end{array}$ & $105-130$ & 00 & 00 & 20 & 66.66 \\
\hline $\begin{array}{c}\text { Good } \\
\text { QOL }\end{array}$ & $79-104$ & 00 & 00 & 10 & 33.33 \\
\hline $\begin{array}{c}\text { Moderate } \\
\text { QOL }\end{array}$ & $53-78$ & 20 & 66.66 & 00 & 00 \\
\hline $\begin{array}{c}\text { Poor } \\
\text { QOL }\end{array}$ & $27-52$ & 10 & 33.33 & 00 & 00 \\
\hline $\begin{array}{c}\text { Very Poor } \\
\text { QOL }\end{array}$ & $1-26$ & 00 & 00 & 00 & 00 \\
\hline
\end{tabular}

Table 4, shows thata high percentage of orphan children (66.66\%) had a moderate quality of life and some of them (33.33\%) had a poor quality of life, whereas a high number of non-orphan children $(66.66 \%)$ had a very good quality of life and some of them (33.33\%) had a good quality of life.

As shown in Table 5, the highest mean percentage of orphan children $(57.43 \%)$ was found for the physical domain with a mean and SD of 17.23 and 3.9012 respectively, followed by the environmental domain (57.1\%) with a mean and SD of 17.13 and 3.70 respectively, social domain $(25.66 \%)$ with a mean and SD of 7.7 and 2.07 respectively, overall domain (13.22\%) with a mean and SD of 3.96 and 1.06, psychological domain (3.70) with a mean and SD of 13.76 and 2.72 respectively.

Among non-orphan children, the highest mean percentage of children (110.43\%) belonged to the environmental domain with a mean and SD of 33.13 and 3.83 respectively, followed by the physical domain (97.76\%) with a mean and SD of 29.33 and 3.31 respectively, psychological domain (83.43\%) with a mean and SD of 25.03 and 2.64 respectively, social domain $37.53 \%$ with a mean and SD of 11.26 and 1.36 respectively, and overall domain $(26.66 \%)$ with a mean and SD of 8 and 1.31 respectively. 
Table 5.Comparison between Mean, SD, and Mean Percentage of Total Quality of Life

\begin{tabular}{|c|c|c|c|c|c|c|c|}
\hline \multirow{2}{*}{ Area } & Maximum & \multicolumn{3}{|c|}{ Orphan Children } & \multicolumn{3}{c|}{ Non-orphan Children } \\
\cline { 3 - 9 } & Score & Mean & SD & Mean \% & Mean & SD & Mean \% \\
\hline $\begin{array}{l}\text { QOLscores among Orphan } \\
\text { and Non-orphan children }\end{array}$ & 130 & 59.8 & 11.43618 & 199.33 & 106.7667 & 11.14074 & 37.1358 \\
\hline
\end{tabular}

Table 6.Association of the Stress Level Scores of Orphan Children with their selected Socio-demographic Variables

\begin{tabular}{|c|c|c|c|c|c|}
\hline $\begin{array}{c}\text { S. } \\
\text { No. }\end{array}$ & $\begin{array}{c}\text { Socio-demographic } \\
\text { Variables }\end{array}$ & Df & $\begin{array}{c}\text { Chi-square } \\
\text { Value }\end{array}$ & Table Value & Significance \\
\hline 1. & Age & 3 & 0.0408 & 7.82 & $P<0.05 \mathrm{NS}$ \\
\hline 2. & Gender & 1 & 0.6693 & 3.84 & $\mathrm{P}<0.05 \mathrm{NS}$ \\
\hline 3. & Religion & 3 & 0.1653 & 7.82 & $\mathrm{P}<0.05 \mathrm{NS}$ \\
\hline 4. & Educational standard & 4 & 0.0408 & 9.49 & $\mathrm{P}<0.05 \mathrm{NS}$ \\
\hline 5. & Duration of stay in orphanage & 3 & 0.0753 & 7.82 & $\mathrm{P}<0.05 \mathrm{NS}$ \\
\hline 6. & Parental living status & 1 & 0.0699 & 3.84 & $\mathrm{P}<0.05 \mathrm{NS}$ \\
\hline 7. & Hobbies & 4 & 0.1653 & 9.49 & $\mathrm{P}<0.05 \mathrm{NS}$ \\
\hline
\end{tabular}

Table 7.Association of the Quality of Life Scores of Orphan Children with their selected Socio-demographic Variables

\begin{tabular}{|c|c|c|c|c|c|}
\hline S. No. & Socio-demographic Variables & Df & Chi-square Value & Table Value & Significance \\
\hline 1. & Age & 3 & 0.4185 & 7.82 & $P<0.05$ NS \\
\hline 2. & Gender & 1 & 0.4192 & 3.84 & $P<0.05$ NS \\
\hline 3. & Religion & 3 & 0.3717 & 7.82 & $P<0.05$ NS \\
\hline 4. & Educational standard & 4 & 0.8203 & 9.49 & $P<0.05$ NS \\
\hline 5. & Duration of stay in orphanage & 3 & 0.4185 & 7.82 & $P<0.05$ NS \\
\hline 6. & Parental living status & 1 & 0.1562 & 3.84 & $P<0.05$ NS \\
\hline 7. & Hobbies & 4 & 0.4185 & 9.49 & $P<0.05$ NS \\
\hline
\end{tabular}

H1. There will be a significant association between quality of life and stress among orphan and non-orphan children with their selected socio-demographic variables. The hypothesis was tested by using chi-square test.

Table 6, depicts the findings regarding the association of the stress scores with the orphan children's socio-demographic variables. It shows that there was no significant association between the stress scores and their socio-demographic variables.

Thus the hypothesis $\mathrm{H} 1$ is not accepted, and is rejected.

Table 7, depicts the findings regarding the association of the quality of life scores with the orphan and non-orphan children's socio-demographic variables. It shows that there was no significant association between the quality of life scores with their selected socio-demographic variables.
Thus the hypothesis $\mathrm{H} 1$ is not accepted, and is rejected.

\section{Discussion}

The findings related to the comparison of the level of stress among the orphan and non-orphan children reveal that most of the orphan children (76.66\%) had moderate stress, $23.33 \%$ of them had high stress, and there were no children with low-level stress. Among the non-orphan children, majority (90\%) had moderate stress, $10 \%$ had low-level stress, and there were no children with high-level stress.

The present study is supported by a descriptive study conducted by Nyamakapa CA to determine the stressrelated emotional and developmental disorders among 294 orphan children in the age group of 6-12 years in Sharkia governorate. An assessment of depression, anxiety, stress, low self-esteem, and developmental disorders using an 
appropriate standardised scale revealed that the prevalence rate of depression was $21 \%$, anxiety and stress was $45 \%$, low self-esteem was $23 \%$, and developmental disorder was $61 \%$. The study concluded that although the basic material needs could be met, orphans in orphanages were almost totally separated from the outside world and could not access normal families and social relations. This would very likely harm their personality and social skills in adulthood. ${ }^{7}$

The findings related to the comparison of quality of life among orphan and non-orphan children reveal that a high percentage of orphan children (66.66\%) had a moderate quality of life and some of them(33.33\%)had a poor quality of life, whereas a high number of non-orphan children (66.66\%) had a very good quality of life and some of them (33.33\%) had a good quality of life.

The present study is supported by a cohort study on 'Quality of Life of orphan adolescents with Perceived Disabilities'. It showed that twenty-one percent of all orphan students reported having one or more physical, emotional, or learning disabilities. Adolescents with disabilities reported lower QOL than adolescents without disabilities. However, self-rated health, depressive symptoms, and contextual variables were significant covariates in the relationship between disability and QOL. These findings suggest channels to improve the QOL of orphan adolescents with disabilities. Specifically, reducing social and environmental barriers to promote inclusion of adolescents with disabilities in school, family, and community activities is one practical avenue for reducing disparities in the quality of life. ${ }^{8}$

The results related to the comparison between mean, $\mathrm{SD}$, and mean percentage of total quality of life scores illustrate that the total mean percentage of the quality of life of orphan children was $199.33 \%$, SD was 11.43618 , and mean was 59.8. For non-orphan children, mean, SD, and mean percentage of quality of life was $106.7667,11.14074$, and 37.1358.

This study is supported by a comparative study conducted on Social Competence and Quality of Life among Orphans and Non-Orphans. The tools used for the present study were personal data sheet, SCS scale developed by Sreechithra VG \& Sabeena PK (2014) and Quality of Life (QoL) Scale developed by Dr Vandana Kaushik and Ms Purva Jaggi (2008). Samples were collected using convenient sampling method. The statistical technique used for the analysis was t-test. Results indicated that there is no significant difference among orphans and non-orphans in their level of social competence. However, a significant difference was found among orphans and non-orphans in the quality of life. ${ }^{9}$

The findings related to the comparison between domain wise mean, SD, and mean percentage of total quality of life scores among orphan and non-orphan children reveals that the highest mean percentage of orphan children $(57.43 \%)$ was found for the physical domain with a mean and SD of 17.23 and 3.9012 respectively, followed by the environmental domain (57.1\%) with a mean and SD of 17.13 and 3.70 , social domain $(25.66 \%)$ with a mean and SD of 7.7 and 2.07 respectively, overall domain (13.22\%) with a mean and SD of 3.96 and 1.06 respectively, and psychological domain (3.70) with a mean and SD of 13.76 and 2.72 respectively.

Among non-orphan children, the highest mean percentage of children (110.43\%) belonged to the environmental domain with a mean and SD of 33.13 and 3.83respectively, followed by the physical domain (97.76\%) with a mean and SD of 29.33 and 3.31 respectively, psychological domain (83.43\%) with a mean and SD of 25.03 and 2.64 respectively, social domain (37.53\%) with a mean and SD of 11.26 and 1.36 respectively, and overall domain $(26.66 \%)$ with a mean and SD of 8 and 1.31 respectively.

\section{Conclusion}

The study findings revealed that orphan children had moderate stress and poor quality of life as compared to non-orphans. Orphan concerns included feeling different from other children, stress, loneliness, stigmatisation, and lack of visit of relatives and support. Orphan children need to be indulged in various institutional activities, such as school training programmes, vocational and life skill training, and cultural and sports activities.

\section{Limitations}

The study was limited to:

- The orphan children who were residing in orphanage and non-orphan children residing in selected areas of Bagalkot.

- The orphan and non-orphan children aged between 10 and 16 years.

- The orphan and non-orphan children who were able to speak and understand Kannada

\section{Source of Funding: Self \\ Conflict of Interest: None}

\section{References}

1. Bhat AA, Rahman S, Bhat NM. Mental Health Issues in Institutionalized Adolescent Orphans. Int J Ind Psych 2015; 3(1): 57-77.

2. Singh A, Suvidha. Well Being of Orphan: A Review on Their Mental Health Status. Int J Sci Res Sci Tech 2016; 2(5): 2395-6011.

3. Orphan Statistics, Facts and Figures. (2012). Retrieved November 4, 2017, Devi B, Reddy VS. Stress and Coping Strategies Among Orphan Children. Paripex-Ind J Res 2017; 6(8). 
4. Datta P, Ganguly S, Roy BN. The prevalence of behavioural disorders among the children under parental care and out of parental care: A Comparative Study in India. Int J Pediatr Adolesc Med 2018; 5(4): 145-151.

5. Kaur R, Vinnakota A, Panigrahi S, Manasa RV. A Descriptive Study on Behavioral and Emotional Problems in Orphans and Other Vulnerable Children Staying in Institutional Homes. Indian J Psychol Med 2018; 40(2): 161-168.

6. Birhanu F. A comparative cross sectional study on psychological well being of orphan and non orphan children. Current Psych 2010; 17(2): 342-344.

7. Nyamukapa CA, Gregson S, Lopman B et al. Orphan psycho social distress; theoretical frame work tested with data. Am J Public Health 2008; 98(1): 133-141.

8. Centers for Disease Control and Prevention (CDC). Measuring Healthy Days: Population Assessment of Health Related Quality of Life. Atlanta, GA; CDC; 2000.

9. Abdussalam M. Social Competence and Quality of Life: A Comparative Study among Orphans and NonOrphans. Phonix - Int J Psychol Soc Sc 2017; 1(3). 